\title{
APLICABILIDADE DA TECNOLOGIA NO ENSINO DE LÍNGUA PORTUGUESA COMO RECURSO DE APRENDIZAGEM NA LEITURA
}

\author{
Gerson de Sousa Batista ${ }^{1}$ \\ Aretuza Silva de Figueredo ${ }^{2}$ \\ Djimara de Assis Rocha de Figueiredo 3 \\ Luciene pereira Braga ${ }^{4}$ \\ Francisco Silva Gomes ${ }^{5}$ \\ Thiago dos Santos Nobre 6
}

\begin{abstract}
RESUMO: O presente artigo procurou investigar sobre a utilização das tecnologias no ensino de Língua Portuguesa, uma vez que a leitura e a escrita praticadas na tela dos aparelhos tecnológicos têm sido observadas como método inevitável, frente a realidade atual. Tendo em vista uma nova formação de alunos com pouco interesse pela leitura, os educadores viram a necessidade de criar estímulos de maneira atrativa e interativa com novas formas de ler e escrever. Em razão disso, as Tecnologias de Comunicação e Informação, conhecidas como tecnologia da informação, tiveram seus recursos explorados em todo campo onde a humanidade atua, porém é no campo da educação que essa pesquisa manteve seu foco. As tecnologias são um conjunto de ferramentas de informação: como o computador, o celular, [o tablete], a TV e suas vantagens, como e-mail, bate-papo, aprendizagem de línguas, blogs e hipertextos (BEATO, 2009), que visa facilitar várias ações na vida das pessoas, utilizando-se de aparelhos de última geração.
\end{abstract}

Palavras-chaves: Tecnologia. Ensino. Língua Portuguesa.

\section{INTRODUÇÃO}

Diante do cenário do ensino atual, as tecnologias mostram na prática um processo importante que é tirar o aluno da rotina de suas aulas tradicionais. No entanto, é fácil perceber que "as tecnologias sozinhas não mudam a escola, mas trazem mil

\footnotetext{
${ }^{\mathrm{I}}$ Formado em Direito pela Universidade Estadual do Piauí e em Letras Português pela Universidade Federal do Piaui. Email:adv.gerson38@gmail.com.

${ }^{2}$ Formada em Enfermagem pela Universidade Federal de Alfenas. E-mail: aretuzasilvadefigueiredo@gmail.com.

3 Formada em Licenciatura Plena em Matemática pela Universidade Estadual do Piauí. E-mail: Djimara_rocha@hotmail.com.

${ }^{4}$ Formada em Licenciatura Plena em Pedagogia pela Universidade Estácio de Sá. E-mail: lucienepb@gmail.com.

${ }^{5}$ Formado em Licenciatura Plena em Pedagogia pela Universidade Estadual do Piaui. E-mail:gomesfsil@gmail.com.

6 Formado em Análise e Desenvolvimento de Sistemas pelo Instituto Federal de Rondônia. E-mail: Tsnobre9o@gmail.com.
} 
possibilidades de apoio ao professor e de interação com [...] os alunos" (MORAN; MASETTO; BEHRENS, 2003), principalmente, na prática de leitura e escrita.

As novas tecnologias se expandiram no contexto escolar, tornando-se um apoio pedagógico, despertando o interesse dos alunos e professores pelas novas ferramentas tecnologias que tem favorecido no processo de leitura e escrita no ensino de Língua Portuguesa.

Os procedimentos técnicos desenvolveram-se bastante nos últimos anos sobretudo motivados pelo ensino remoto ocasionado pela pandemia e ancorado na necessidade de uma nova forma de ensino e adaptação aos tempos da tecnologia pedagógica.

Nos tempos atuais, o ser humano, o cenário e suas ações têm passado por rápidas e grandes transformações, atualizando-se em várias áreas do conhecimento. Para Machado (2017, p.I) essas mudanças vêm motivando as pessoas a utilizarem novas práticas de ensinar e de aprender, tendo em vista o progresso na sociedade atual.

Com o passar dos tempos, a sociedade testemunhou que "os avanços tecnológicos permitiram que a leitura e a escrita fossem desenvolvidas em outros suportes, como a tela" dos aparelhos tecnológicos (MACEDO; JUNIOR; VELOSO, 2013, p.212). Conhecer e entender como utilizar as ferramentas tecnológicas tem sido visto como ações indispensáveis, tanto quanto foi à necessidade de ler e de escrever (OLIVEIRA, 2019, p.7).

A utilização do computador progrediu significativamente com relação às cansativas atividades realizadas nos livros tradicionais, uma vez que aquela motiva e atrai mais seus usuários (GARCIA, 2012, p.22) a realizarem atividades pedagógicas, considerando as transformações oriundas das tecnologias e das práticas sociais.

Com as mudanças nos modos de interação da sociedade, "a tecnologia da leitura e da escrita, como mediadoras do ser e agir do homem sobre o mundo, não estão imunes aos efeitos do surgimento das tecnologias digitais". (FERRAZ, 2019, p,150). Tal 
reconhecimento faz referência às inúmeras funções e facilidades disponíveis nos dispositivos eletrônicos na hora de escrever e ler na tela dos dispositivos tecnológicos

De acordo com Dariva (2010, p.7):

[...] Os recursos da tecnologia nos oferecem certa [...] possibilidade de escrever e reescrever um texto na tela do computador, alterar o tamanho e o estilo das letras, sublinhar, colorir trechos, podendo ter uma qualidade de layout quase perfeita dependendo da habilidade de cada um.

A autora destaca, na informação supradita, umas das contribuições que a escrita digital possibilita aos usuários: a formatação e edição, uma alternativa que visa organizar e melhorar o aspecto dos textos eletrônicos de acordo com os conhecimentos da pessoa.

A utilização das tecnologias no meio educativo, também, oferece aos estudantes conteúdos ilimitados de textos quando estão conectados a uma rede de internet. Alinhados a essa informação, vários autores relatam que "a comunicação através da internet criou novos horizontes de utilização do código escrito, o que acaba exigindo do autor-leitor novas habilidades da escrita, como também da leitura" (COSTA; MARTINS; QUEIROZ, 2015, p.2) na tela dos dispositivos inteligentes.

As contribuições advindas das tecnologias, no processo de leitura são praticadas e pautadas nas transformações que o mundo atual vem apresentando nas suas práticas sociais. E à medida que o tempo vai passando, cada dia o estudante, o professor e o cidadão são - praticamente - forçados a evoluir, devido às influências modernas que as tecnologias proporcionam para a quebra de novos paradigmas na educação.

Porém, de acordo com Rusto e Rubio (2013, p.6) “o processo de ensinoaprendizagem de leitura e de escrita na escola não pode ser configurado como um mundo à parte e não ter a finalidade de preparar o sujeito para a realidade na qual se insere.". Ou seja, o ensino, ao fazer uso das tecnologias e das ferramentas adequadas, permite ao professor conduzir o aluno a experimentar vários recursos na hora de ensinar, além de retirá-lo da uniformidade.

Para Santos (2010, p.I), essa "inclusão no mundo digital oportuniza ao sujeito experimentações, desafios e novas possibilidades de usos sociais da leitura e escrita.". A 
exemplo da leitura e escrita digital como práticas de letramento, que proporcionam evoluções na interação social e representam ações significativas no desenvolvimento das pessoas, dentro de uma sociedade que integre comunicações reais e virtuais através das TICs (CHAGAS, 2014, p.331).

Diante do exposto, entende-se que as TICs provocaram progressões reais na aquisição do conhecimento, sendo que a internet, bem como sua facilidade de acesso, proporciona para os jovens diferentes formas de ler e de escrever (LEAL E LIMA, 2015, p. 36890).

Para uma melhor compreensão sobre as informações supraditas, Oliveira (2019, p.4) cita que "vivemos em uma época marcada pela cultura digital e, muitas vezes, não nos damos conta ou paramos para refletir sobre como as influências e implicações das novas tecnologias de informação e comunicação estão conectadas aos nossos hábitos cotidianos."

Seguindo essa visão, percebe-se que a internet além de ser um "recurso dinâmico, atraente, atualizadíssimo, [...] que possibilita o ingresso a um número ilimitado de informações e dá a oportunidade de contatar todas as grandes bibliotecas do mundo inteiro.” (MORAN, 2006, p.I6o). Além de vir sendo atribuída como um recurso capaz de potencializa e incentivar o processo de leitura e escrita digital, tendo em vista novos patamares e acesso a novos paradigmas na educação.

Mesmo com essa nova realidade de ensino e aprendizagem ajustada às novas tecnologias nas escolas, ainda assim, é uma temática que gera uma polêmica acompanhada de vertentes: ler e escrever na tela do computador são vistos como novas práticas que ajudam o aprendizado.

De acordo com a Unesco (2014, p.22), "no mundo desenvolvido, a transição para livros didáticos digitais em ambientes de educação formal é uma das tendências mais bem estabelecidas da aprendizagem móvel.”. E mesmo que a leitura digital ainda possua algumas concepções contra, ainda vale a pena investir nesse tipo de prática, com o objetivo de aumentar o grau de interatividade entre os usuários. 
Utilizar a ferramenta certa para educar pode ser um fator essencial para o professor desempenhar melhor seu trabalho e manter-se ativo, perante, as constantes mudanças da contemporaneidade. É preciso entender a relação entre a tecnologia e seus alunos, para conseguir melhor resultados nos processos pedagógicos, além de ensinar de forma crítica - os meios necessários para o aluno absorve o assunto.

$\mathrm{Na}$ busca de melhorar os métodos das instituições de ensino, a temática da leitura e escrita nos aparelhos tecnológicos vem sempre acompanhada de reflexões e questionamentos sobre o seu verdadeiro potencial. E com as seletas ideias reunidas neste trabalho, foi possível constatar que as TICs aliadas à leitura e a escrita, permitem proporcionar novas experiências e facilitar a vida do ser humano, tanto quanto cidadão, como estudante.

Os professores de Língua Portuguesa são os principais autores quando se trata de ensinar os alunos a ler e a escrever. Esses ensinamentos exigem, desses profissionais, estarem capacitados para ensinar, uma vez que, nesse contexto, estão inseridos outros tipos de uso social da língua - como os textos digitais (MAJORA, 2018).

Essas considerações visam situar os educadores, tendo em vista as constantes transformações ocorridas em todas as esferas sociais. Sendo que, no âmbito educacional, não é diferente. As instituições de ensino, os professores e todos que pensam em melhorar a educação, precisam sempre estar passando por um processo de atualização nos métodos e nos materiais didáticos. E uma das melhores alternativas de potencializar o ensino-aprendizagem, inserindo as TICs como apoio pedagógico, principalmente explorando a leitura e escrita dos alunos.

Assim, com essa evolução dos meios de comunicação digitais, tem surgido uma série de recursos linguísticos que, consequentemente, ocasionou outros tipos de produção textual, determinados pelas transformações da própria escrita (RODRIGUES, 2010).

Essas mudanças vêm ocorrendo paulatinamente e são marcadas pela presença em massa dos aparelhos tecnológicos, em praticamente, todos os ambientes e seguimentos 
da vida humana. Por esse motivo, o novo hábito de leitura e de escrita digital dos estudantes de Língua Portuguesa vem se mantendo, modificando e se adaptando às novas estruturas de leitura e escrita.

Sendo assim, vale destacar que os dispositivos levam os fatos até as pessoas, deixando-as informadas de forma automática. E um processo parecido com esse é utilizado na educação à distância, e acontece quando a leitura e atividades podem ser realizadas de outros lugares e de outros aparelhos com acesso a internet (DOCTRINA, 2014).

Analisando a ideia da autora, fica fácil concordar com seus pensamentos, quando comparada a atual situação que se encontra o ensino-aprendizagem. Nesse caso, é importante lembrar que as instituições de ensino estão trabalhando de forma parcial, pois passaram por várias e rápidas transformações e adaptações no sistema de ensino tradicional para o on-line. E isso só foi permitido, porque os estudos e as leituras dos alunos passaram a ser feitos na tela dos aparelhos tecnológicos, e as TICs passaram a ter maior notoriedade por mostrar, ao mundo, as enumeras vantagens dos aparelhos tecnológicos.

Vale lembrar, que as variadas formas de leitura e escrita existentes no contexto social, recebem apoio de vários meios de última geração, como a internet, o celular e o computador para serem utilizados na comunicação (RODRIGUES, 2010).

Todos esses recursos, citados acima, são muito valorosos porque oferecem para os alunos e para a sociedade geral as vantagens de ler, escrever, estudar e, de forma imediata, enviar para qualquer pessoa o conteúdo através de

e-mails ou até mesmo por mensagens instantâneas. E isso tem impactado diretamente na educação.

Outra vantagem dessas TICS está na escrita digital, pois ao digitar um texto, a pessoa, dependendo de sua habilidade, poderá fazer varias alterações como: a escolha, o tamanho, a cor da fonte e a chance de reescrita para melhorar a aparência do documento. (DARIVA, 20I0). 
A inclusão das TICs no ensino aprendizagem também permite ao aluno receber um aprendizado com conteúdo mais atualizados, uma vez que a leitura através de sites educativos traz uma maior variedade de tipos de textos, que permite otimizar a interação entre os alunos e o professor de forma mais dinâmica e prazerosa.

A utilização do computador progrediu significativamente com relação às cansativas atividades realizadas nos livros tradicionais, uma vez que aquela motiva e atrai mais seus usuários (GARCIA, 2012, p.22) a realizarem atividades pedagógicas, considerando as transformações oriundas das tecnologias e das práticas sociais.

Conforme já mencionado, a necessidade de novas formas de aprendizagem não surgiu à toa. $\mathrm{O}$ ser humano, em busca de ações que visam facilitar os afazeres do dia a dia, viu nas tecnologias excelente oportunidade que favorecesse a realização de várias tarefas ao mesmo tempo. Além disso, o uso da tecnologia permite levar a seus usuários, vantagens no desenvolvimento de sua formação, tanto no âmbito social, como no âmbito educativo. Uma dessas vantagens seria a leitura digital, que utiliza aparelhos tecnológicos como suporte para oferecer aos leitores a oportunidade de comportar vários livros digitais para ler onde, como e quando quiser. Essa nova modalidade de leitura, traz maior dinamicidade e proporciona aos seus leitores outras possibilidades de ler na tela dos aparelhos tecnológicos, denominada de leitura não linear.

\section{REFERÊNCIAS BIBLIOGRÁFICAS}

ASSUNÇÃO, M.S.H. Narrativas digitais: uma proposta para leitura e produção de textos multimodais. 2018. I76 f. Dissertação (Mestrado Profissional em Letras em Rede Nacional - PROFLETRAS) - Faculdade de Letras, Programa de Pós Graduação em Mestrado Profissional em Letras e em Rede Nacional, Universidade Federal de Alagoas, Maceió, 2018. Disponível em:http://www.repositorio.ufal.br/handle/riufal/3186 . Acesso em: o6 de jul. de 2020 .

AZEVEDO, E.N.; STEYER, F.A. Os Desafios da Escola Pública Paranaense na Perspectiva do Professor PDE. O Uso da Tecnologia no Ensino e Aprendizagem da Leitura. Versão online ISBN 978-85-8015-080-3, 2014. 
BOTTENTUiT; JUNIOR, J.B. Do Computador ao Tablet: Vantagens Pedagógicas na Utilização de Dispositivos Móveis na Educação. Revista Educaonline, v. 6, p. I25-I49, 2012.CHAGAS, M.F.L. et al. Atuação Docente na Inter-relação dos Letramentos Alfabético e Digital no Ciberespaço. Holos, Natal, v. 6, p.ı, dez. 2014.

DARIVA. A Leitura na Era Digital: Uma Proposta de Trabalho Pedagógico com o Gênero Discursivo HD. Caderno O Professor PDE e os Desafios da Escola Pública Paranaense. Secretaria de Educação do Estado do Paraná, Volume i, 2oro. Disponível em:

http://www.diaadiaeducacao.pr.gov.br/portals/cadernospde/pdebusca/producoes_pde/ 2010/2010_unicentro_port_artigo_seila_maria_de_oliveira.pdf. Acesso em: i4 de jul. de 2020 .

evista Eletrônica Saberes da Educação, volume 4, $\mathrm{n}$ I, 2013. Disponível em: http://docs.uninove.br/arte/fac/publicações/pdf/v4-nI-2013/Marcia.pdf. Acesso em: I4 de Ago. de 2020.

PEDRÓ, F. A Tecnologia e as Transformações da Educação. Madrid: Fundación Santillana, 2016.

PEREIRA, L. Leitura, Gêneros Textuais e Novas Tecnologias. Revista de Educação Ciência e Tecnologia, Canoas, v.I, n.I, 2012.

SANTOS, F.M.A. Interferências da Linguagem Digital na Aquisição do Português Escrito. In: Simpósio Hipertexto e Tecnologias na Educação, 3. 2010, Recife. Anais. Disponível em: http:// https://docplayer.com.br/8415096-Interferencias-da-linguagemdigital-na-aquisicao-do-portugues-escrito.html. Acesso em: 13 de jul. de 2020

SILVA, C.G. A Importância do Uso das TICS Na Educação. Revista Científica Multidisciplinar Núcleo do Conhecimento. Ano 03, Vol. 16, pp. 49-59, Ago. de 2018. ISSN:2448-0959

SILVA, C.G. A Importância do Uso das TICS Na Educação. Revista Científica Multidisciplinar Núcleo do Conhecimento. v.ı, ed. o8, p.oo-oo, ago. de 2018. 